\title{
O quiasma e a experiência da infinitude nas obras de Rainer Maria Rilke e Clarice Lispector
}

\author{
Alexandre Rodrigues da Costa ${ }^{1}$
}

\begin{abstract}
É sempre um pouco mais longe que o lugar onde olho, onde o outro olha, que se encontra o vidente que sou - Pousado no visível, como um pássaro, preso ao visível, não no visível. E, contudo, em quiasma com ele.
\end{abstract}

Merleau-Ponty

Novalis, repetidas vezes, em seus fragmentos, enuncia um pensamento que será de grande importância para se entender como dois autores tão diferentes um do outro, como podem ser Rainer Maria Rilke e Clarice Lispector, problematizam em suas obras a relação do sujeito com o mundo. Tal pensamento, que o poeta alemão teoriza em seus escritos, antecipa não só as preocupações de Rilke e de Clarice sobre a questão do sujeito e o espaço à sua volta como guarda semelhanças com algumas reflexões ligadas à fenomenologia da percepção de Maurice MerlauPonty. No fragmento 20 de suas "Observações entremescladas", Novalis assim expõe: "A sede da alma é ali onde o mundo interior e o mundo exterior se tocam. Onde eles se interpenetram - está ela em cada ponto da interpretação" (Hardenberg, 1988, p. 45).

É interessante notar que Novalis não nega o elemento racional desse contato do mundo interior com o mundo exterior, já que é exatamente a consciência da percepção que garantiria a união com o mundo: "O mais arbitrário dos preconceitos é que ao ser humano seja negada a faculdade de ser fora de si, de estar em consciência além dos sentidos. O ser humano é capaz de ser em cada instante um ser supra-sensível. Sem isso não seria cidadão do mundo - seria um animal" (Hardenberg, 1988, p. 49). Embora pareça que a fala de Novalis discorde do pensamento de Rilke e de Clarice quanto à questão do racional como entendimento do mundo, veremos que a consciência não é totalmente negada por ambos escritores, já que ela aponta para o entrecruzamento do sujeito com o objeto de sua percepção, para a possibilidade de romper os limites que separam um do

\footnotetext{
${ }^{1}$ Doutor em letras e professor da Escola Guignard e da Universidade do Estado de Minas Gerais (UEMG), Belo Horizonte, MG, Brasil. E-mail: rodriguescosta@hotmail.com
} 
outro. Quando Maurice Merleau-Ponty nos diz que "o interior e o exterior são inseparáveis", que "o mundo está inteiro dentro de mim e eu estou inteiro fora de mim" (Merleau-Ponty, 1999, p. 546), suas proposições imediatamente nos lembram a de Novalis, com o detalhe de que o filósofo francês se detém na maneira como se dá esse contato entre o interno e o externo, como o corpo se realiza entre as coisas, pois para ele

Visível e móvel, meu corpo está no número das coisas, é uma delas; é captado na contextura do mundo, e sua coesão é a de uma coisa. Mas já que vê e se move, ele mantém as coisas em círculo à volta de si; elas são um anexo ou um prolongamento dele mesmo, estão incrustadas na sua carne, fazem parte da sua definição plena, e o mundo é feito do próprio estofo do corpo (Merleau-Ponty, 1984, p. 89).

Essa consciência de que as coisas são um anexo e um prolongamento do corpo é possível perceber tanto na obra de Rilke quanto na de Clarice, já que, em ambas, as coisas não são percebidas como inertes, mas estendidas até nós como uma espécie de ponto de reunião, ou seja, algo que exige nossa presença, nosso olhar. Não se trata de personificálas, de inseri-las em um contexto humano, mas de uma mútua identificação, no sentido de vê-las como seres a partir dos quais nossa existência se faz necessária. Para Merleau-Ponty, isso se deve à forma como nos posicionamos frente ao mundo, como "as coisas são o prolongamento do meu corpo e o meu corpo é o prolongamento do mundo" (Merlau-Ponty, 2000, p. 230). ${ }^{2}$ É através desse duplo movimento que surge essa superfície de contato que o filósofo francês chama de quiasma, "carne do mundo", cujo conceito aponta para o instante no qual a percepção do sujeito se entrelaça com o objeto de sua atenção. Essa diluição de fronteiras entre o corpo e o mundo faz com que a percepção não se centralize apenas no sujeito, mas também nas coisas. Os textos de Rilke e de Clarice tornam presente, dessa forma, o espaço onde se reúnem tanto a percepção do sujeito quanto a percepção que as coisas têm desse sujeito. Paul de Man, ao dedicar um estudo

\footnotetext{
2 Edward Snow, no prefácio que serve à sua tradução dos Novos poemas, comenta: "A interanimação do objeto e da consciência é, finalmente, o grande tema dos Novos poemas, apesar de sua aparente devoção aos estados de retirada, separação e isolamento. Na sua forma mais radical, buscam abrir as dimensões daquilo que um fenomenólogo como Merleau-Ponty chamaria de 'mundo vivido', onde sujeito e objeto são aspectos inseparáveis de uma unidade engendrada imaginativamente" (Snow, 2001, p. 50, tradução nossa).
} 
sobre a obra de Rilke, conseguiu precisar como essa interseção entre o sujeito e o objeto, o quiasma, é possível de ser rastreada, em seus aspectos retóricos, ${ }^{3}$ ao longo de seus poemas:

A figura determinante da poesia de Rilke é a do quiasma, o cruzamento que inverte os atributos de palavras e coisas. Os poemas são compostos de entidades, objetos e sujeitos, que se comportam como palavras, que "brincam" de linguagem de acordo com as regras da retórica, assim como uma pessoa brinca de bola de acordo com as regras do jogo (Man, 1996, p. 56).

A análise que Paul de Man faz da obra de Rilke ajuda-nos a refletir sobre o quiasma não simplesmente como um elemento estruturador de seus poemas, mas também como aquilo que permite abordar a predileção do poeta pelas coisas, no momento em que escreve sobre elas, a partir de uma exterioridade ficcionalizada. Antes de ser uma simples inversão de atributos, o quiasma nos ajuda a perceber como se dá o entrelaçamento do sujeito com o mundo, como um se torna prolongamento do outro, como se dá "a ramificação de meu corpo e a ramificação do mundo e a correspondência do seu dentro e do meu fora, do meu dentro e do seu fora" (Merlau-Ponty, 2000, p. 132). Dessa forma, o quiasma adquire dois sentidos na obra de Rilke, que, como veremos, estão também presentes em Clarice Lispector: um que aponta para a própria construção de sua escrita e outro que possibilita ver como ocorre o desaparecimento da voz particular do sujeito, já que o quiasma, "ao cruzar os atributos de interior e exterior, leva à aniquilação do sujeito consciente" (Man, 1996, p. 54). Esse cruzamento do interior e do exterior é constantemente explorado pelo poeta, ao longo de sua obra, como pode ser percebido neste poema, datado de junho de 1924:

O espaço através do qual os pássaros se lançam não é o espaço verdadeiro, que te revela a forma. Lá fora, deves recusar-te para desaparecer, para não mais retornar.

O espaço extrai de nós as coisas e as traduz: para que te tenha êxito o ser de uma árvore lança o espaço interior em volta dela, esse espaço que está em ti. Se tentas retê-lo,

\footnotetext{
${ }^{3}$ Semelhante ao que Paul de Man faz em relação à obra de Rilke, Nádia Gotlib (1989) analisa a presença do quiasma como parte da construção dos textos de Clarice Lispector.
} 
ele não se confina. Apenas na imagem

de tua renúncia, ele realmente se torna árvore (Rilke, 1965, p. 167-168)

O poema, sem título, revela como se dá esse contato do sujeito com o mundo a partir de um espaço que se realiza na recusa de um pensamento objetivo, de um mundo inteiramente pronto. O que se tem, aí, é a realização do espaço como "o grande sossego das coisas que não são forçadas a nada" (Rilke, 1995, p. 110-111), no sentido de que sua forma não está condicionada por aquilo que acreditamos ser a tradução de um pensamento racional, mas por um ver cuja definição está muito próxima da de Merleau-Ponty: “a visão não é um certo modo do pensamento ou da presença a si: é o meio que me é dado de estar ausente de mim mesmo, de assistir de dentro a fissão do Ser, só no termo da qual eu me fecho sobre mim" (Merleau-Ponty, 1984, p. 108). O espaço, que Rilke evoca em seu poema e ao longo de sua obra, é exatamente isto: estar ausente de si mesmo. Mas um ausentar-se no qual, por exemplo, "a paisagem se pensa em mim e sou sua consciência" (Merleau-Ponty, 1984, p. 119), de forma que as identidades se perdem para se encontrarem, se perdem para criarem um espaço no qual as coisas ao mesmo tempo subsistem por si mesmas e se entrelaçam ao olhar de quem as percebe.

Esse espaço seria aquilo que Rilke chama de Weltinnenraum, o espaço interior do mundo, no qual aquele que olha e o que é olhado não estão em oposição, e onde os limites que definem o interior e o exterior apagam-se em favor de uma identidade única. Nesse sentido, o olhar se constrói na evocação de sua própria ausência e o que, a princípio, poderia ser vazio acaba sendo um todo preenchido por uma existência baseada na renúncia, na abdicação dos limites que definem e garantem o reconhecimento da identidade na recusa da do outro. Essa negação da primazia do eu sobre as coisas é possível, porque, na obra de Rilke, segundo Paul de Man,

a assimilação do sujeito ao espaço não ocorre realmente como o resultado de um intercâmbio analógico, mas por uma apropriação radical que de fato implica a perda, o desaparecimento do sujeito como sujeito. Ele perde a individualidade de uma voz particular transformando-se em nada mais, nada menos que a voz das coisas, como se o ponto de vista central tivesse sido deslocado do eu para as coisas externas. Da mesma forma, essas coisas externas 
perdem sua solidez e se tornam tão vazias e vulneráveis como nós mesmos (Man, 1996, p. 53-54).

Se essa perda da individualidade, em um certo momento, fundamenta a obra de Rilke, talvez não seja diferente com a de Clarice Lispector, cujos textos apontam constantemente para a diluição do sujeito no mundo, em que o "eu" se configura em uma posição de igualdade com as coisas, pois, usando as palavras da autora, "só se aproximando com humildade da coisa é que ela não escapa totalmente" (Lispector, 1999, p. 25). Da mesma forma que em Rilke, o fascínio pelo mundo que se abre à sua volta leva Clarice a teorizar, em vários momentos de sua obra, sobre a distância que define os seres, o olhar que apaga os limites entre uma identidade e outra. Poderíamos dizer, nesse sentido, que há aquele mesmo impulso de redefinição do sujeito que ocorre em Rilke, para quem o tornar-se coisa passa por uma "realidade intensificada pela sua vivência do objeto, até tornar-se indestrutível" (Rilke, 1996, p. 50). Essa indestrutibilidade, para Clarice Lispector, passa pela redefinição do sujeito no momento em que este se confronta com o mundo. É o que nos narra, de forma quase autobiográfica, Clarice, em Um sopro de vida, através de sua personagem Ângela: "O objeto - a coisa - sempre me fascinou e de algum modo me destruiu" (Lispector, 1999b, p. 104). E destruir, aqui, talvez signifique a afirmação de um corpo momentâneo, perdido entre as coisas:

Olhar a coisa na coisa: o seu significado íntimo como forma, sombra, aura, função. De agora em diante estudarei a profunda natureza morta dos objetos vistos com delicada superficialidade, e proposital, porque se não fosse superficial se afundaria em passado e futuro da coisa. Quero apenas o estado presente ou nascida da natureza e das coisas feitas pelo homem. Esse sentir é uma revolução para mim de tão nova (Lispector, 1999b, p. 106).

Esse novo olhar, que Clarice de certa forma conceitualiza, pode ser pensado como uma maneira não de reconhecer na coisa o reflexo de um mundo interior, mas de aceitar o inesperado como o que se encontra próximo aos olhos e se confunde com o corpo, apagando a fronteira que fica entre o sujeito e o mundo. ${ }^{4}$ Trata-se de render o olhar

\footnotetext{
${ }^{4}$ Outra maneira de se pensar esse apagamento das fronteiras entre o sujeito e o mundo reside na articulação que Clarice faz, em alguns de seus textos, do mise en abyme, como pode ser percebido no estudo que Mariângela Alonso (2004) dedica ao assunto, no seu artigo "Dimensões especulares em A paixão segundo GH, de Clarice Lispector".
} 
às coisas que estão em volta, de se revelar nelas a partir de uma "identificação mútua", de maneira que o sujeito, ao lançar o olhar para as coisas, também se veja como coisa: "Eu sou um objeto que vê outros objetos. Uns são meus irmãos e outros inimigos. Há também objeto que não diz nada. Eu sou um objeto que me sirvo de outros objetos, que os usufrui ou os rejeita" (Lispector, 1999b, p. 109).

Ao se considerar como um objeto, o sujeito supera a distância do que lhe chama a atenção. Nesse estado de contemplação, no qual se considera um igual entre os objetos, usando as palavras de Schiller, "a contemplação (reflexão) é a primeira relação liberal do homem com o mundo que o circunda" (Schiller, 1963, p. 117), pois a contemplação afasta o objeto e "faz dele sua propriedade verdadeira e inalienável na medida em que o protege da paixão" (Schiller, 1963, p. 117). Assim, a perda da individualidade, quando o eu é deslocado para a exterioridade das coisas, nada mais é do que a tomada de consciência "da função de um olhar que nada tem a fazer, de um olhar que não olha mais para um objeto particular e sim olha o mundo" (Bachelard, 1993, p. 213). E olhar o mundo requer, a princípio, um olhar que não se retém a si mesmo, mas que, entregue ao mundo à sua volta, ainda é capaz de fazer escolhas, de eleger os objetos sobre os quais pode se deter. É o momento em que a interioridade se conjuga com o exterior e o mundo se torna um espaço de transfiguração, onde, nas palavras de Merleau-Ponty, "a transcendência é a identidade na diferença” (Merleau-Ponty, 2000, p. 207), o que retoma o conceito de quiasma, assim exposto pelo filósofo francês:

O quiasma não é somente troca eu-mundo (as mensagens que recebe, é a mim que chegam, as mensagens que recebo é a ele que chegam), é também troca de mim e do mundo, do corpo fenomenal e do corpo "objetivo", do que percebe e do percebido: o que começa como coisa termina como consciência da coisa, o que começa como "estado de consciência" termina como coisa. (Merleau-Ponty, 2000, p. 200)

Ora, se o quiasma se estabelece como troca, só a partir do contraponto com aquilo que não é o sujeito, pode-se buscar a não identidade, esse instante de revelação, no qual o "eu" se vê fora, no qual sua consciência se faz na identidade das coisas ao redor e estas surgem a partir da identidade do sujeito que as observa, as toca. Nesse sentido, a tentação pelo desconhecido e a lembrança de tudo que aflige apagamse, quando o Weltinnenraum se realiza através do quiasma, ou seja, 
quando entrecruzamos o mundo interior com o mundo exterior através do desdobramento de nós mesmos e das coisas em seu fora e dentro.

Em Clarice, se o quiasma não ocorre de maneira tão evidente como ocorre na obra de Rilke, ${ }^{5}$ é porque sua presença está intrinsecamente ligada à poética da autora. Os textos de Clarice nos quais o quiasma se deixa perceber são aqueles que problematizam a relação sujeito/mundo. Nesse caso, os objetos, as coisas, surgem como uma forma de questionar a própria identidade, na medida em que o sujeito tem sua consciência confrontada com o limite que se interpõe entre ele e o mundo à sua volta: “À beira de eu estou mim. É para mim que vou. E de mim saio para ver. Ver o quê? Ver o que existe" (Lispector, 1996, p. 91). De todos os sentidos, em Clarice, ver é o que mais favorece esse confronto e a transformação deste em quiasma.

No texto "A geleia viva", do livro Para não esquecer, esse confronto se dá pelo espelhamento: "Quando olhei-a, nela vi espelhado meu próprio rosto mexendo-se lento na sua vida" (Lispector, 1999a, p. 67). Ao ser defrontado consigo mesmo, o mundo surge para esse sujeito, hesitante entre a perspectiva de integrar-se ao todo pela vida ou pela morte, como revelação: "foi que vi os olhos do escuro. Não 'olhos no escuro'. Mas os olhos do escuro. O escuro me espiava com dois olhos grandes, separados. A escuridão, pois, também era viva. Aonde encontraria eu a morte? A morte era geleia viva. Vivo estava tudo" (Lispector, 1996, p. 67). É bom observar que, aqui, não se trata de personificar a escuridão, pois ela não é tratada como subordinada a uma razão, mas, ao contrário, é aquilo que confronta o sujeito com suas próprias razões, através do olhar, pois, segundo Roland Barthes, "talvez eu seja, sem cessar e intensamente, olhado pelo que está escondido. A lição a se tirar daqui seria que, à força de olhar, talvez nos esqueçamos de que também somos olhados. Ou então: no verbo 'olhar', as fronteiras do ativo e do passivo não são nítidas” (Barthes, 1990, p. 278).

Essa indefinição das fronteiras de quem olha e do que é olhado faz da visão, percepção explorada por Clarice desde seus primeiros livros, uma forma de lançar-se além do estado de coexistência com as coisas, de alcançar um sentido que se constrói a partir da falta de sentido e que o ultrapassa, "todo momento de 'falta de sentido' é exatamente a assustadora

\footnotetext{
${ }^{5}$ Paul de Man, em sua análise sobre o quiasma em Novos poemas, afirma: "Cada um desses poemas se isola em sua própria autossuficiência como descrição de um objeto ou cena particular, e cada poema afirma em seus próprios termos o enigma do quiasma que os constitui” (Man, 1996, p. 61).
} 
certeza de que ali há o sentido" (Lispector, 1964, p. 35), e que se dá quando o sujeito se perde naquilo que vê, como ocorre em A paixão segundo G.H.: "Não compreendo o que vi. E nem mesmo sei se vi, já que meus olhos terminaram não se diferenciando da coisa vista" (Lispector, 1964, p. 13-14). Esse perder-se na coisa nada mais é do que "um encontro entre 'nós' e 'aquilo que existe'” (Merleau-Ponty, 2000, p. 156), já que, ao olhar o mundo, o mundo também nos olha, no sentido de que a percepção dele não se faz apenas em nós, mas se constrói a partir de um entrecruzamento que, nos textos de Clarice, pode ser lido como transmutação:

Uma pantera negra enjaulada. Uma vez olhei bem nos olhos de uma pantera e ela me olhou bem nos meus olhos. Transmutamonos. Aquele medo. Saí de lá toda ofuscada por dentro, o " $X$ " inquieto. Tudo se passara atrás do pensamento. Estou com saudade daquele terror que me deu trocar de olhar com a pantera negra. Sei fazer terror (Lispector, 1998, p. 73).

Para que ocorra essa troca, é preciso que, aí, o sujeito busque uma existência impessoal, similar ao que ocorre em A paixão segundo G.H., em que a narradora afirma: "os seres existem os outros como modo de se verem" (Lispector, 1964, p. 76). Nessa existência, na qual "tudo olha para tudo, tudo vive o outro" (Lispector, 1964, p. 66), a despersonalização surge como forma de fugir à cisão entre sujeito e objeto, de se despojar daquilo que se constitui como barreira ao ser: "A despersonalização como a destituição do individual inútil - a perda de tudo o que se possa perder e, ainda assim, ser" (Lispector, 1964, p. 176). Despersonalização como identidade pura, na qual, segundo Benedito Nunes, "se anula a diferença entre o sujeito interno e o objeto externo, ambos compenetrados numa visão recíproca sem transcendência" (Nunes, 1995, p. 73). Sentido este que podemos também encontrar na imagem da pantera enjaulada, do famoso poema de Rilke:

\section{A pantera}

De tanto olhar as grades seu olhar esmoreceu e nada mais aferra.

Como se houvesse só grades na terra: grades, apenas grades para olhar.

A onda andante e flexível do seu vulto em círculos concêntricos decresce, dança de força em torno a um ponto oculto 
no qual um grande impulso se arrefece.

De vez em quando o fecho da pupila se abre em silêncio. Uma imagem, então, na tensa paz dos músculos se instila para morrer no coração (Campos, 2001, p. 57).

Tanto no breve trecho de Água viva quanto no poema de Rilke, o que está em jogo é a noção de identidade de um sujeito que se detém sobre o mundo. Em ambos os textos, é o olhar que possibilita o deslocamento do "eu" para as coisas externas, que em vez de fechar-se em seu mundo, é arremessado para o que está ao seu redor. Para tal experiência, Clarice se utiliza da imagem do inquieto " $\mathrm{X}$ ", representação gráfica daquilo que ela define como transmutação: "Quando eu vejo, a coisa passa a existir. Eu vejo a coisa na coisa. Transmutação" (Lispector, 1998, p. 105). Esse transmutar-se na coisa vista passar a ser a forma de libertar-se de um pensamento regido pela necessidade de entendimento, no qual a compreensão elimina qualquer possibilidade de falta de sentido. Postura que em muito se assemelha à proposta pela "doutrina" Zen. ${ }^{6}$ Segundo D. T. Suzuki, o Zen "afirma que a razão pela qual não podemos alcançar uma completa compreensão da verdade é devida à nossa irracional aderência a uma interpretação lógica das coisas" (Suzuki, 1971, p. 80-81). Ora, o que Rilke e Clarice não buscam, nesse debruçar sobre a realidade, é exatamente a confirmação de um "eu" que se espelhe nas coisas, que tenha a pretensão de rendê-las através de um olhar objetivo, pois se a objetividade existe nesses dois escritores ela é, como nos diz a narradora de A paixão segundo G.H., "a objetividade forçada de lidar com aquilo que já não era eu" (Lispector, 1964, p. 26). Sobre esse eu que se coloca em questionamento, Benedito Nunes analisa:

A diferença entre sujeito e objeto reaparece interiormente como desdobramento do Eu num Ele, que exerce a ação de existir. Nem G.H. nem a barata existem simplesmente ou apenas coexistem; uma é para si mesma aquilo que se espelha no olhar da outra. O Eu não se relaciona com um Tu mas com um Ele que também é. Ação e paixão do sujeito, que se torna agente e paciente, a sua existência é a existência do Outro que ele já é em si mesmo. Daí o regime

\footnotetext{
${ }^{6}$ Sobre a questão do Zen budismo na obra de Clarice Lispector, ver o livro Zen e a poética autoreflexiva de Clarice Lispector: uma literatura de vida e como vida, de Igor Rossoni (2002).
} 
reflexivo forçado que a narradora empresta aos verbos ser e existir, e a dupla reflexividade do verbo olhar (Nunes, 1995, p. 63).

Essa dupla reflexividade do olhar, esse lidar com o que não é o "eu", faz com que o sujeito seja, nas palavras de Clarice Lispector, "tão maior do que aquilo que eu chamava de 'eu' que, somente tendo a vida do mundo, eu me teria" (Lispector, 1964, p. 124). Uma das formas de se configurar literariamente essa troca de lugares, tornar a existência do sujeito a existência do outro, é fazer com que a palavra seja atraída pelas coisas e nelas resida, de maneira que o sujeito possa afirmar: "Sou: o que vi" (Lispector, 1998, p. 67). Transmutar-se na coisa vista resulta, portanto, na perda de identidade, naquilo que Clarice entende por despersonalização, cujo sentido aproxima-se do que ocorre na doutrina Zen:

Quando já não nos identificamos com a ideia de nós próprios, toda a relação entre sujeito e objeto conhecedor e conhecido sofre uma súbita e revolucionária modificação. Torna-se uma relação real, uma unidade relacional em que o sujeito cria o objeto tanto quanto o objeto cria o sujeito (Watts, 1979, p. 148-149).

Mas para que essa entrega ocorra, é necessário que o sujeito, em certa medida, desapareça no objeto. É a partir dessa falta de identidade que a narradora de A paixão segundo G.H. afirma: "O mundo se me olha. Tudo olha para tudo, tudo vive o outro; neste deserto as coisas sabem as coisas" (Lispector, 1964, p. 66). Podemos entender o poema de Rilke, “A pantera", como o olhar de um sujeito que não visa simplesmente descrever uma pantera, pois sua identidade se transmuta no olhar do animal à sua frente, no instante em "que não existe identidade e nãoidentidade nem não-coincidência, existe o fora e o dentro girando um em torno do outro" (Merleau-Ponty, 2000, p. 237). O olhar da pantera só é apreensível se aquele que está diante dela se rende à sua armadilha, se perde na falta de contingência de uma linguagem que confunde o dentro e o fora, o avesso da própria imagem.

Não seria possível pensar que, a partir dessa perspectiva, o sujeito que observa a pantera, de certa forma, não reflete o comportamento do leitor que se debruça sobre o poema e assim tenta configurar através da leitura a imagem da pantera? $\mathrm{O}$ ver, como aquilo que se funda em um jogo da linguagem, é o que dá forma ao poema de Rilke. Mas é um ver que não se destina a descrever a pantera, pois o que ele representa é a interioridade da pantera que se oferece ao leitor. Se há uma visão externa da pantera, é porque ela se realiza apenas na segunda estrofe, nas outras, o que ocorre é 
a visão que a pantera tem do mundo a sua volta, "grades, apenas grades para olhar", "Uma imagem, então, / na tensa paz dos músculos se instila / para morrer no coração". O poema se constrói, portanto, a partir da frustração, de um ver que não se cumpre, de uma escrita que não se rende gratuitamente a um ler. Não é à toa que o poema se inicie com grades e termine com uma imagem não revelada, pois o objeto almejado não é a pantera, mas o que esta vê. Daí que o poema termine justamente na dissolução da pantera em seu próprio olhar, pois, conforme David E. Wellbery, "a atividade do poeta parece ser movida por um desejo que não é realizável por ser o objeto desejado - a linguagem tornada corpo - algo impossível" (Wellbery, 1998, p. 186). Enquanto o poema nos oferece, em sua abertura, a imagem das grades, em seu final, ele nos nega qual seria a imagem. Uma leitura apressada poderia sugerir que isso ocorre, pois o sujeito se apieda da pantera enjaulada, poupando-a em seu segredo. Mas a partir de uma análise que considere o ver em relação direta com o ler, é possível perceber que, na verdade, a inversão do quiasma é o que permite o olhar da pantera se desdobrar no plano formal e ficcional, de tal forma que a maneira como o poema se constrói corresponde exatamente ao que está sendo dito, ou seja, um universo liberto do raciocínio só pode se estabelecer para o animal no enigma de uma imagem que se cala. Esse calar, usando novamente palavras de David E. Wellbery,

significa que a poética de Rilke questiona o valor da intuição enquanto presentificação imediata de um objeto visível. Os próprios textos atribuem à experiência de presença em que se funda o conceito tradicional do poema-coisa uma posição sistemática da meta impossível do desejo; é evidente que, a partir dessa posição, a experiência da presença não mais é capaz de oferecer a base adequada para a interpretação ou para descrição do texto (Wellbery, 1998, p. 189-190).

Esse questionamento que a poética de Rilke faz da presentificação imediata de um objeto visível retira sua obra de leituras tendenciosas, que a veem como a afirmação da poesia como algo que pode escapar ao caráter alienado e artificial da realidade humana. Por muito tempo, a poesia de Rilke ficou marcada como promessa de uma salvação que só é possível através da linguagem poética, como se em momento algum o poeta não colocasse em desconfiança a legitimidade de sua arte, o que Paul de Man vem a demonstrar em sua célebre análise do soneto do Cavaleiro, da primeira parte dos Sonetos a Orfeu: "a 
verdade da figura se revela como uma mentira no exato momento em que se afirma na plenitude de uma promessa" (Man, 1996, p. 73). Essa promessa, que de Man insere dentro da perspectiva desagregadora da mentira, concorda, de certa maneira, com os questionamentos que Clarice faz da palavra:

A palavra apenas se refere a uma coisa e esta é sempre inalcançável por mim. Cada um de nós é um símbolo que lida com símbolos tudo ponto de apenas referência ao real. Procuramos desesperadamente encontrar uma identidade própria e a identidade do real. E se nos entendemos através do símbolo é porque temos os mesmos símbolos e a mesma experiência da coisa em si: mas a realidade não tem sinônimos (Lispector, 1998, p. 73).

O que se extrai de Clarice, da mesma forma que de Rilke, é uma postura que coloca em desconfiança o signo linguístico, a referência ao real, já que, lembrando as palavras de Blanchot, "pela consciência somos entregues à representação, mantemo-nos diante de nós, mesmo quando olhamos desesperadamente para fora de nós" (Blanchot, 1987, p. 131). Quando Rilke deixa que silenciosamente a imagem morra no coração da pantera ou mostra que a figura do cavaleiro formada pelas estrelas é uma mera ilusão de sentidos, sua poética questiona exatamente essa procura por uma identidade própria e a identidade do real. Nesse sentido, Rilke e Clarice não estão tão afastados de um poeta como Mallarmé, já que em ambos há a consciência de que "o nome é um acréscimo e impede o contato com a coisa" (Lispector, 1964, p. 141), "o nome é um intervalo para a coisa" (Lispector, 1964, p. 141). Essa proximidade com Mallarmé torna-se mais evidente com relação à Clarice, já que, em vários momentos, é possível encontrar, em sua obra, um certo incômodo, similar ao do poeta francês, em usar as palavras. Incômodo para o qual Clarice parece buscar antídoto, em seus últimos livros, através do contato da literatura com a música e as artes plásticas, apontando, como no poeta francês, para uma evocação ao silêncio:

A beatitude começa no momento em que o ato de pensar liberouse da necessidade de forma. A beatitude começa no momento em que o pensar-sentir ultrapassou a necessidade de pensar do autor - este não precisa mais pensar e encontra-se agora perto da grandeza do nada. [...] A verdadeira incomensurabilidade é o 
nada, que não tem barreiras e é onde uma pessoa pode espraiar seu pensar-sentir (Lispector, 1998, p. 82).

Isso que Clarice chama de beatitude ou estado de graça e o que os críticos sinalizam em sua obra com o nome de epifania vai contra o simples pensar, a consciência volta para si mesma, através da qual as palavras afastam o objeto, pois "seu ofício é atrair o olhar sobre elas mesmas para desviá-lo da coisa de que falam" (Blanchot, 1997, p. 38). Daí que "a coisa nunca pode ser realmente tocada" (Lispector, 1964, p. 139), apreendida, e o que baste seja se render a ela, abandonando o nome, a identidade que nos difere dela e nos dá a ilusão de proteção:

Eu me ultrapasso abdicando de meu nome, e então sou o mundo. [...] Não usar palavras é perder a identidade? é se perder nas essenciais trevas daninhas? Perco a identidade do mundo em mim e existo sem garantias. (Lispector, 1964, p. 65-65)

E novamente nos encontramos com o inquieto " $\mathrm{X}$ ", o quiasma, pois, para que o quiasma ocorra, não basta apenas o sujeito abdicar-se de seu nome, perder a identidade, mas perder a identidade do mundo no eu, conjugando a perda nesta tão banalizada palavra: amor. Palavra que Rilke assim relaciona, em um poema de 1914, com o olhar, e do qual reproduzimos as últimas estrofes:

Por que, eis, há para o olhar um limite.

E o mundo suficientemente olhado

quer no amor cumprir-se.

A obra do olhar está realizada, empreende agora obra de coração sobre as imagens em ti, essas cativas; porque se tens domínio sobre elas, não as conhece ainda (Rilke, s/d, p. 52).

Entender que o conhecimento da imagem passa não pelo seu aprisionamento, ou seja, pela consciência de sua realização, é colocar em questionamento as tentativas de interpretação do mundo, pois o que Rilke nos parece dizer com estes versos é que "amor é quando não se dá nome à identidade das coisas" (Lispector, 1964, p. 87). Cumprir em amor o mundo, através do olhar, é afirmar que, se as palavras não bastam para conhecer as coisas, é necessário ver-se fora, "misturando o que se vê com o que se sente" (Lispector, 1964, p. 63), ou, conforme as palavras de Leonardo da Vinci, "o amante se acerca à coisa amada, como o sentido à sensível, e com ela se une, formando uma coisa só" (Vinci, 1997, p. 47). E nesse formar uma 
coisa só, as linhas que definem o eu e o mundo, o dentro e o fora, não são mais claras, o quiasma surge como indefinição de limites, ou melhor, como falta de limites, já que amante e coisa amada, ao se unirem, tornam-se inacabados, "estranhos um ao outro, mas, todavia, absolutamente juntos, em "simultaneidade"' (Merleau-Ponty, 1984, p. 108). O que prevalece, a partir dessa nova perspectiva, é a incerteza. Diante da incerteza, o Weltinnenraum torna-se um processo inacabado, quando interpretado como perda de referencialidade, o que críticos como Blanchot e Paul de Man exploraram na obra do poeta a partir da perspectiva da incerteza. Assim, Paul de Man diz acerca do Weltinnenraum:

Rilke também chama essa perda de referencialidade pelo ambivalente termo "Interioridade" ("innen entstehen", "Weltinnenraum", etc.), que então não designa a presença-a-si de uma consciência, mas a inevitável ausência de um referente confiável. Designa a impossibilidade da linguagem poética de se apropriar de qualquer coisa, seja como consciência, objeto, ou uma síntese de ambos (Man, 1996, p. 65).

O Aberto, que aparece nas Elegias de Duíno, ajuda-nos a entender o Weltinnenraum no momento em que se afirma como força que ultrapassa a significação da coisa, sendo a própria coisa se afirmando como incerteza: "Sempre é mundo / e nunca Lugar Algum sem Nada" (Rilke, 2002, p. 173). Esse lamento por não se alcançar o nada, em um mundo regido pelos imperativos da razão, origina-se quando o sujeito tem no Aberto a certeza de que "toda compreensão súbita é finalmente a revelação de uma aguda incompreensão. Todo momento de achar é um perder-se a si próprio" (Lispector, 1964, p. 14). Perder-se a si próprio é fugir da presença-a-si de uma consciência, é colocar em desconfiança a certeza das próprias crenças, o que a palavra designa, pois "aproximarmo-nos do Aberto como algo seguro seria ter a certeza de que não atingimos o Aberto" (Blanchot, 1997, p. 135). Daí a necessidade de manter a dúvida constante, de não estabelecer limites entre aquele que olha e aquilo que é visto.

Rilke e Clarice, em seu olhar lançado sobre o mundo, parecem, de acordo com as palavras de Meyer Schapiro sobre Cézanne, "realizar o conceito filosófico da percepção estética como puro saber involuntário" (Schapiro, 1996, p. 65). Afirmação que o crítico norte-americano complementa com uma pergunta: "mas o estilo de 'saber', embora pessoal, não é modelado em parte pela personalidade dos objetos de 
atenção, por seu significado e seu interesse para a mente perceptiva?" (Schapiro, 1996, p. 65). A essa pergunta, poderíamos responder sim, já que a escolha das coisas, em Rilke e Clarice, não se faz ao acaso, mas se ajusta a uma lógica construída através da especulação estética que se dilui no movimento da escrita, pois segundo Adorno, "quanto mais integradas as obras de arte, tanto mais nelas se desintegra o que as constitui" (Adorno, 1993, p. 67), de tal maneira que sobram apenas vestígios que um olhar mais atento pode descobrir.

Nesse sentido, a respeito da imagem da barata, em A paixão segundo G. H. ou a do epilético, em Os Cadernos de Malte Laurids Brigge, podemos dizer que "sempre se encontrará esse elemento pitoresco e surpreendente misturado ao horror e instalando, entre leitor e tema, o véu de uma linguagem que controla seu próprio domínio representacional" (Man, 1996, p. 39). Controle que é exercido, usando expressão de Merleau-Ponty, pelo "anonimato inato do Eu-mesmo" (Merleau-Ponty, 2000, p. 135), quando aquele que vê tem seu corpo entrelaçado às coisas a partir de um olhar desdobrado, refletido, de dentro para fora e de fora para dentro. Nesse espelhamento da visão, o que se destaca é o sentir-se olhado pelas coisas, que surge no momento em que o "não ver de fora" torna presente o olhar do mundo sobre si mesmo e não mais saibamos quem vê e quem é visto. Dessa forma, os poemas de Rilke ou as narrativas de Clarice tornam-se a definição de um ver e de um olhar que se confundem, pois o racional e o que foge à razão dão à palavra seu sentido mais pleno. É na palavra que observador e coisa observada se mesclam, a identidade se perde na imagem, o corpo rodeado pelo visível se torna invisível.

\section{Referências}

ADORNO, Theodor W. (1993) Teoria estética. Tradução de Artur Morão. Lisboa: 70.

ALONSO, Mariângela (2004). Dimensões especulares em A paixão segundo GH, de Clarice Lispector. Revista do SELL, Uberaba, v. 4, n. 2.

BACHELARD, Gaston (1993). A poética do espaço. Tradução de Antonio de Pádua Danesi. São Paulo: Martins Fontes.

BARTHES, Roland (1990). O óbvio e o obtuso: ensaios críticos III. Tradução de Léa Novaes. Rio de Janeiro: Nova Fronteira. 
BLANCHOT, Maurice (1987). O espaço literário. Tradução de Álvaro Cabral. Rio de Janeiro: Rocco.

BLANCHOT, Maurice (1997). A parte do fogo. Tradução de Ana Maria Scherer. Rio de Janeiro: Rocco.

CAMPOS, Augusto de (2001). Coisas e anjos de Rilke. São Paulo: Perspectiva.

GOTLIB, Nádia Battella (1989). Uma aprendizagem dos sentidos. In: GOTLIB, Nádia Battella. Três vezes Clarice. Rio de Janeiro: Escola de Comunicação da UFRJ. v. 7, p. 12-24.

HARDENBERG, Friedrich von (Novalis) (1988). Pólen: fragmentos, diálogos, monólogo. Tradução, apresentação e notas de Rubens Rodrigues Torres Filho. São Paulo: Iluminuras.

LISPECTOR, Clarice (1964). A paixão segundo G. H. Rio de Janeiro: Editora do Autor.

LISPECTOR, Clarice (1998). Água viva. Rio de Janeiro: Rocco.

LISPECTOR, Clarice (1999a). Para não esquecer. Rio de Janeiro: Rocco.

LISPECTOR, Clarice (1999b). Um sopro de vida. Rio de Janeiro: Rocco.

MAN, Paul de (1996). Alegorias de leitura: linguagem figurativa em Rousseau, Nietzsche, Rilke e Proust. Tradução de Lenita R. Esteves. Rio de Janeiro: Imago.

MERLEAU-PONTY, Maurice (1984). Textos escolhidos. Traduções e notas de Marilena de Souza Chauí, Nelson Alfredo Aguilar, Pedro de Souza Moraes. 2. ed. São Paulo: Abril Cultural.

MERLEAU-PONTY, Maurice (1999). Fenomenologia da percepção. Tradução de Carlos Alberto Ribeiro de Moura. São Paulo: Martins Fontes.

MERLEAU-PONTY, Maurice (2000). O visível e o invisível. 4. ed. Tradução de José Artur Gianotti e Armando Mora d'Oliveira. São Paulo: Perspectiva.

NUNES, Benedito (1995). O drama da linguagem: uma leitura de Clarice Lispector. São Paulo: Ática.

RILKE, Rainer Maria (1965). Sämtliche Werke: Band II. Frankfurt: Insel.

RILKE. Rainer Maria (1995). Rodin. Tradução de Daniela Caldas. Rio de Janeiro: Relume-Dumará.

RILKE. Rainer Maria (1996). Cartas sobre Cézanne. Tradução e prefácio de Pedro Süssekind. 3. ed. Rio de Janeiro: 7Letras.

RILKE. Rainer Maria (2002). Os sonetos a Orfeu e elegias de Duíno. Tradução e introdução de Karlos Rischbieter com Paulo Gargunkel. Rio de Janeiro: Record. 
RILKE. Rainer Maria (s.d.). Querida Lou. Tradução de Antônio Gonçalves. Sintra: Colares.

ROSSONI, Igor (2002). Zen e a poética auto-reflexiva de Clarice Lispector: uma literatura de vida e como vida. São Paulo: Editora da Unesp.

SCHAPIRO, Meyer (1996). A arte moderna: séculos XIX e XX. Tradução de Luiz Roberto Mendes Gonçalves. São Paulo: Edusp.

SCHILLER, Friedrich (1963). Cartas sobre a educação estética da humanidade. Introdução e notas de Anatol Rosenfeld. São Paulo: Herder.

SNOW, Edward (2001). Introduction. In: RILKE, Rainer. New poems. New York: North Point.

SUZUKI, Daisetz Teitano (1971). Introdução ao zen-budismo. Tradução e apresentação de Murilo Nunes de Azevedo. Prefácio de C. G. Jung. Rio de Janeiro: Civilização Brasileira.

VINCI, Leonardo da (1997). Obras literárias, filosóficas e morais. Apresentação de Carmelo Distante. Tradução de Roseli Sartori. São Paulo: Hucitec.

WATTS, Alan W. (1979) O budismo zen. Lisboa: Presença.

WELLBERY, David E. (1998) Neo-retórica e desconstrução. Organização de Luiz Costa Lima e Johannes Kretschmer. Rio de Janeiro: Editora da UERJ.

Recebido em 18 de abril de 2017.

Aprovado em 13 de agosto de 2017.

\section{resumo/abstract/resumen}

\section{O quiasma e a experiência da infinitude nas obras de Rainer Maria Rilke e Clarice Lispector}

Alexandre Rodrigues da Costa

Este artigo analisa como o quiasma, tanto em uma perspectiva retórica quanto fenomenológica, estabelece relações entre as obras de Rainer Maria Rilke e de Clarice Lispector, no momento em que os dois autores usam a palavra como forma de alcançar uma identificação plena do eu com o mundo.

Palavras-chave: quiasma, Weltinnenraum, despersonalização, Rainer Maria Rilke, Clarice Lispector. 
The chiasm and the experience of infinitude in the works of Rainer Maria Rilke and Clarice Lispector

Alexandre Rodrigues da Costa

This article analyzes how the chiasm, both from a rhetorical and a phenomenological perspective, establishes relationships between the works of Rainer Maria Rilke and Clarice Lispector, insofar as the two authors use the word as a way to achieve a full identification of the self with the world.

Keywords: chiasm, Weltinnenraum, depersonalization, Rainer Maria Rilke, Clarice Lispector.

\section{El quiasma y la experiencia de la infinitud en las obras de Rainer Maria Rilke y de Clarice Lispector}

Alexandre Rodrigues da Costa

En este trabajo se analiza cómo el quiasma, tanto en la retórica como perspectiva fenomenológica, establece relaciones entre las obras de Rainer Maria Rilke y Clarice Lispector, cuando los dos autores utilizan la palabra como una manera de lograr una plena identificación del yo con el mundo.

Palabras clave: quiasma, Weltinnenraum, despersonalización, Rainer Maria Rilke, Clarice Lispector. 